\title{
ORIGINAL ARTICLE Parents with a spinal cord injury
}

\author{
A Rasul and F Biering-Sørensen
}

Study design: This is a cross-sectional questionnaire.

Objectives: The objective of this study was to describe the impact of parenting young children with a spinal cord injury (SCl) on various life situations (for example, personal, vocational and social).

Setting: Community; Denmark.

Methods: A postal survey was designed to collect data in persons with SCl regarding the following: (1) socio-demographics, injury characteristics and parental status; (2) employment status; (3) environmental adjustments to support parenting roles; (4) childcare institution use and experiences; (5) network support for parenting; and (6) parenting advice for others.

Results: A total of 62 persons (58\% men) responded to the survey, with $56 \%$ having paraplegia and $44 \%$ having tetraplegia. The majority of men (83\%) and women (62\%) were employed during the first 10 years of their child's lives. Half of the sample (50\%) did not find the accessibility of their childcare institutions optimal to accommodate their $\mathrm{SCl}$. Only $22 \%$ felt that they got answers about being a parent with an SCl. The main advice provided by the sample to those considering of becoming a parent was encouragement, whereas the advice for municipalities was to provide more funding support for personal assistance and aids.

Conclusion: The present study provides insights into the challenges and satisfaction of being a parent post SCl across various life domains. Overall, the sample was very satisfied with their parenting role. The major issue noted for parents with $\mathrm{SCl}$ was the lack of support from local municipalities.

Spinal Cord (2016) 54, 396-401; doi:10.1038/sc.2015.197; published online 15 December 2015

\section{INTRODUCTION}

As the prognosis after spinal cord injury (SCI) is improving, the number of individuals with SCI who want to become parents is increasing. ${ }^{1,2}$ The $U N^{\prime} s$ Convention on the Rights of Persons with Disabilities, Article 23 (Respect for home and family), commits each state to provide the needed support to parents with disabilities in order to make them able to fulfill their parental role. ${ }^{3}$

Recently, the Danish Institute for Human Rights released a report about individuals with physical and intellectual disabilities rights to get support for parenting, which was in accordance with the UN's Convention on the Rights of Persons with Disabilities. The report concluded that municipalities have difficulties in providing the needed assistance to parents with disabilities as the legislation is not clear enough. Several cases in which children have been forcibly taken away from their parents with disabilities were studied. Two parents who were in a wheelchair (because of hemiplegia and cerebral palsy) had their children taken away, as it was deemed that their disability prevented them from providing the basic needs for their children. Disturbingly, their children were taken away before an investigation was conducted about how it would be possible to compensate for the parents' disability. One could question whether it would have been necessary if these parents had received the right support from their municipalities from the start. ${ }^{4}$

The aim of this study was to document the impact of parenting young children with an SCI on various life situations. Specifically, we documented the experience of being a parent with an SCI, which included the working conditions, use of personal assistance, aids, childcare institution and support network. Doing so will provide health-care professionals with more knowledge on how to counsel their clients with an SCI who wish to become parents or who are currently parenting. Furthermore, the findings could serve to inform individuals who already have a child/children, and then sustain an SCI on how to adapt to the new situation. Although there are several studies $^{1,5-8}$ about parenting after an SCI, this study provides a contribution to the literature by examining several specific life domains (listed above), for both men and women, impacted by parenting after an SCI.

\section{MATERIALS AND METHODS}

The present study included parents with an SCI from Denmark. The parents were identified using different methods. A recruitment advertisement was published on the official Facebook page of The Danish Spinal Cord Injuries Consumer Association 'Rygmarvskadede $i$ Danmark, RYK' and in their magazine 'RYK!'. Individuals with an SCI followed by the Clinic for Spinal Cord Injuries, Rigshospitalet, and Department of Neurology-Spinal Cord Injury Centre of Western Denmark, Viborg Regional Hospital, were contacted by both telephone and in-person during ordinary consultations or in-patient stay and asked to participate in the study. Some of the individuals followed by the Clinic for Spinal Cord Injuries, who were identified through the Spinal Cord Injury Database, were contacted by telephone. They accepted to receive a questionnaire without any compensation. The questionnaire was distributed and answered during 2014. Inclusion criteria were Danish-speaking individuals with SCI, who used a wheelchair for $1 \mathrm{~h}$ or more a day and who had a child/

Clinic for Spinal Cord Injuries, the NeuroSciense Centre, Rigshospitalet, University of Copenhagen, Copenhagen, Denmark

Correspondence: Dr A Rasul, Clinic for Spinal Cord Injuries, Rigshospitalet (2081), University of Copenhagen, Blegdamsvej 9, Copenhagen 2100, Denmark.

E-mail: ar-89@hotmail.com

Received 27 March 2015; revised 23 September 2015; accepted 24 September 2015; published online 15 December 2015 
children $<10$ years old at the time they started to use their wheelchair because of their SCI.

The questionnaire for the present study was developed with the assistance of a woman with paraplegia with two children. She gave ideas of what kind of problems persons with SCI might encounter as a parent, which helped identify the questions that would be relevant to illustrate these challenges. The questionnaire consisted of seven groups of questions: (1) General information (20 questions); (2)Working Conditions (6 questions); (3) Personal Assistance because of the Child (5 questions); (4) Home adjustments/Mobility Aids (10 questions); (5) Childcare Institution (14 questions); (6) Network (7 questions); and (7) Good Advice for Others (3 questions). A first edition of the questionnaire was e-mailed to four parents with an SCI (of whom three answered). Their responses were used to adjust the questionnaire. The revised questionnaire (Supplementary Appendix 1) was e-mailed (with one reminder) to the same parents, but none responded. These three were included in the study despite the fact that they did not complete the revised version of the questionnaire. To account for this, we reported revised questions for these individuals as 'Unanswered'.

A total of 99 persons (including the four asked to complete the first edition), 50 male and 49 female parents with an SCI, were asked to answer the questionnaire (anonymously if they wished) via e-mail or by post with a prepaid return envelope. A reminder was sent to those who received the request to participate by e-mail approximately $2-4$ weeks following the initial contact. In all, 73 of the 99 persons (74\%) replied, of whom 7 turned out not to fulfill the inclusion criteria and were thus excluded from the data analyses. Four participants declined to participate. The explanations for not participating included that either the questions in the questionnaire were not comparable to their injury, that their life situation did not allow it or that it was mentally stressful to answer the questions. Sixty-two individuals (63\%) of the invited sample completed the questionnaire and met the study's inclusion criteria.

\section{Statistical methods}

Fisher's exact test was used to compare the responses across gender and impairment (paraplegia vs tetraplegia). The level of significance was set at 0.05 . All the stated percentages in the results are based on those who have answered the particular question.

\section{RESULTS}

\section{General information}

The mean age of the responders at the time of the study was 48.1 years (range 29-72 years). The mean time since injury was 24.7 years (s.d. 14.5 , median 24.5 , range $2-55$ years). The mean age of the responders' children was 15.8 years (s.d. 110.5, median 16, range $1-45$ years). At the birth of the first child, among those who had their first child after their SCI, the mean age was 32.5 years (s.d. 8.4, median 36, range 21-54 years). The mean duration of their SCI at the birth of the first child was 16.5 years (s.d. 9.3, median 17, range 3-38 years). In all, $36(58 \%)$ were men and $26(42 \%)$ were women, $34(56 \%)$ had paraplegia and 27 (44\%) had tetraplegia. Fifty-three (87\%) used their wheelchairs permanently and eight $(13 \%)$ used their wheelchair at least $1 \mathrm{~h}$ a day. The number of children, the number of parents who had stepchildren and the number of parents who are or have been single parents are illustrated in Table 1. Forty-three (72\%) had children after their SCI, and seventeen (28\%) had children before they sustained their SCI.

The nonresponder group (of those who received the questionnaire) consisted of 26 individuals. The nonresponder group was similar to the responders regarding gender distribution: 11 (42\%) men and 15 (57\%) women $(P=0.2)$.

\section{Working conditions}

Sixteen $(62 \%)$ of the women and thirty $(83 \%)$ of the men had jobs during the 10 first years of their children's life. Table 2 shows the amount of hours per week, and whether they were able to combine
Table 1 Questions and answers regarding general information

\begin{tabular}{lc}
\hline Question & $n(\%)$ \\
\hline $\begin{array}{l}\text { Gender? }(n=62) \\
\text { Woman }\end{array}$ & $26(42)$ \\
Man & $36(58)$ \\
& \\
Do you have a paraplegia or a tetraplegia? $(n=61)$ & \\
Paraplegia & $34(56)$ \\
Tetraplegia & $27(44)$ \\
Are you a permanent wheelchair user? $(n=61)$ & \\
Yes & \\
No & $53(87)$ \\
How many children do you have? $(n=62)$ & $8(13)$ \\
1 & \\
2 & \\
3 & $20(32)$ \\
4 & $28(45)$ \\
5 & $9(15)$ \\
& $3(5)$ \\
& $2(3)$
\end{tabular}

Do you have stepchildren? $(\mathrm{n}=60)$

Yes

12 (20)

No

48 (80)

Are you or have you been a single parent? $(n=59)$

Yes

$23(39)$

No

$36(61)$

job with parenting, divided by gender. The results show that there was no significant difference between the two genders regarding employment $(P=0.08)$, nor being capable of combining job with parenthood $(P=0.16)$. The comments for the ability of combining work with parenting varied from five expressing 'not being able to work at all' with one of the responders stating 'to not being able to imagine a life without working. The comments also indicated that it was easier for some of the parents to combine a job with parenting with a part-time job or having the opportunity to work from home. It should be noted that a normal fulltime job in Denmark is $37 \mathrm{~h}$.

\section{Personal assistance}

Only 17 (28\%) answered that they have received professional help and that there was no significant difference between those with paraplegia $(21 \%)$ and tetraplegia $(35 \%)(P=0.38)$. Five answered that they had paid for the professional help they received. On the question 'Have you been able to manage the bathing situation of your child alone?' 26 (43\%) answered 'No'. The responders with paraplegia were more capable of managing their child's bathing situation by themselves than those with tetraplegia $(P=0.0005)$. Specifically, only $5(19 \%)$ with tetraplegia were able to manage compared with $21(66 \%)$ of those with paraplegia. Twenty-four of those who were not able to manage the bathing situation of their child mainly got support from their partners. Of those who did not get help from their partners, seven got the help from a personal assistant and one from another family member. A general tendency was that when the children were quite small the parents with an SCI needed help in the bathing situation but the need for help diminished when the children grew older and could be more involved in their self-care. Two of the comments from the respondents also showed that there could be some ambivalence regarding receiving 
Table 2 Questions and answers regarding working conditions

\begin{tabular}{|c|c|}
\hline Question & $n(\%)$ \\
\hline \multicolumn{2}{|c|}{ Have you had a job during your child/children's childhood ( $0-10$ years)? $(\mathrm{n}=62)$} \\
\hline Yes & $46(74)$ \\
\hline No & $16(26)$ \\
\hline \multicolumn{2}{|c|}{$\begin{array}{l}\text { Have you had a job during your child/children's childhood ( } 0-10 \text { years)? Woman } \\
(\mathrm{n}=26)\end{array}$} \\
\hline Yes & $16(62)$ \\
\hline No & $10(38)$ \\
\hline \multicolumn{2}{|c|}{$\operatorname{Man}(n=36)$} \\
\hline Yes & $30(83)$ \\
\hline No & $6(17)$ \\
\hline \multicolumn{2}{|c|}{ If yes, how many hours a week? $(n=46)$} \\
\hline$<20$ & $8(17)$ \\
\hline $20-37$ & $13(28)$ \\
\hline$>37$ & $21(46)$ \\
\hline Varying & $4(9)$ \\
\hline \multicolumn{2}{|c|}{ Have you been able to combine job with parenting? Woman $(n=20)$} \\
\hline Yes & $14(70)$ \\
\hline No & $6(30)$ \\
\hline \multicolumn{2}{|c|}{$\operatorname{Man}(\mathrm{n}=32)$} \\
\hline Yes & $28(87.5)$ \\
\hline No & $4(12.5)$ \\
\hline
\end{tabular}

personal assistance. For instance, one responder noted his ambivalence of receiving support from the BPA (Borgerstyret Personlig Assistance), the citizen-driven personal assistance program. He commented 'Therefore it was a great help with the BPA-system, so I can save the little strength that I have, for my family.'. At the same time, the same person commented that it was a challenge having someone else around their child.

Other notable comments were one person stating that she got bedsores because of the lack of help. Another of the participants wrote that his wife got permission from her work with full salary from the municipalities, in order to meet the family's needs.

\section{Home adjustments and aids}

Thirteen $(30 \%)$ of those who had children after getting their SCI answered that there was a need for home adjustments after the baby was born. However, these adjustments were primarily made at the time of the injury and not because of the birth of their child. There was no significant difference between those with paraplegia $(21 \%)$ and tetraplegia $(9 \%)$ in this respect $(P=0.32)$. The home adjustments made because the children were primarily new furniture: for example, height-adjustable changing table or a cot with wheels.

Fifty-five (92\%) had a car and fifty-two (95\%) of these used either a lift or other aids/equipment in relation to the car. Two parents, who did not have a car, mentioned that they have wished to have one, but that it was too expensive, and the municipality had refused their application for financial help to buy a car. Thirty $(48 \%)$ used one or more of the following aids; three did not know that these existed:

- Height-adjustable baby changing table

- Cot adapted for wheelchair-bound parents
Table 3 The parents' own solution regarding aids that made the daily living easier

Arm rest on the wheelchair (to breastfeed).

Desk as a changing table.

Bathtub on a stand on the same height as the wheelchair.

Ergonomic nursing pillow from the brand 'Cozyfix', good to put on my thighs, to have the child close-both lying and sitting..

Universal elastic belt-brand 'Body Point'. Used to secure the child sitting

in front of the leg/stomach. Used during transport outdoors.

Knee cradle from the brand 'Kayserbetten'.

Child-chair put in a bicycle trailer attached to the wheelchair.

Attached the changing table with two jacks on the wall so that I could

get under it when the boys had to be changed.

Handbike with a child-chair.

Two baby-seats attached behind the mini crosser.

Standing chair.

High-chair that could be adjusted up and down.

Used a sleeping bag when she lay on the floor. Otherwise she

could be raised up with her playpen.

I bought a bed where the side could be removed, in an ordinary store, lifted the child from the floor in a normal pram harness or with the dungarees.

Used a regular baby carrier or a sling, which worked really well because the baby was close to the body and almost sitting on the lap so it does not affect the balance very much.

As a cot we used the baby carriage - it is stable and has the advantage that you can cradle them when they go to sleep and it can be quite close to my bed.

We used a cradle that we hung up on a hook in the ceiling right next to

my bed so that I could take her over to me at night without that I would

need to go out of the bed.

Have not had any tools to lift my kids up from the floor. An experienced wheelchair mother taught me to take hold of the clothes on the baby to raise it from the floor (it requires of course that they can hold their head)..

I had made a beanbag pillow that they sat in; in the sofa-it was incidentally also good for breastfeeding.

I used often a buggy, where they could be at a height so it would be easier for me to lift them up. It also has the advantage that it can be pushed around everywhere.

Stroller from the brand 'Teutonia', with a fixed lift that granted that I could see my child (not as high as prams).

- Baby harness for parents in wheelchair

- Wheelchairs with extra functions: for example, baby chair in front of the wheelchair where the baby is at the same height as the parent

- Aids for lifting the baby from the floor

One answered that they, from the municipality, requested a wheelchair with baby chair in front of the wheelchair where the baby can be at the same height as the parent. She got the answer that such a thing did not exist.

Some of the parents had their own simple solutions for making their daily living easier. Two had bathtubs on a stand at the same height as the wheelchair and one used fabric diapers to lift the child from the floor. More solutions invented by the parents are presented in Table 3.

One of the parents had two of her children forcibly removed for a half year. She commented that she applied to have the aids mentioned in the questionnaire and some home adjustments because of her children. Because she had a personal assistant around the clock, however, she was not granted the home adjustments.

Seventeen $(77 \%)$ of the women could breastfeed without aids/help, and there was no significant difference between women with paraplegia $(85 \%)$ and those with tetraplegia $(50 \% ; P=0.21)$. 


\section{Childcare institution}

Twenty-four answered that their SCI had influenced on their choice of childcare institution. The explanations were mainly that they chose a childcare institution on ground level without stairs and where there was indoor and outdoor access for wheelchairs. Half of the parents with an SCI did not feel that the access to their childcare institutions was such that she/he could get in without extra help consisting of specific environmental adjustments. The main adjustments noted were mainly the installation of a ramp. Twelve of the responders had ramps installed at the childcare institution. Some of the parents mentioned that ramps were already in place. One other problem with the accessibility was issues with opening the door by themselves while sitting in their wheelchair. The doorknobs were placed higher up so that the children could not get out by themselves. The solution was that they called the childcare institution by phone when they arrived so that the staff would come out to the parking lot and receive the child. One-third did not feel that the interiors of their childcare institution were wheelchair friendly.

Only 10 respondents felt that they did not have the same access to the parents' meetings in the childcare institution as their able-bodied peers. The reasons for these difficulties were mainly related to environmental barriers, which included holding meetings in the basement or on the second floors of buildings without elevators. One parent had difficulties in attending the parent meetings because there was no wheelchair-accessible toilet.

Nearly all felt that their child/children's friends could come home to them and play. Only 16 felt that they got special treatment from the parents of their children's' mates in the childcare institutions or school because of his/her SCI, which were perceived mostly in a positive way (for example, being more helpful and open). Only one of the responders experienced negative treatment from other parents because of his SCI. Other experienced insecurity from the able-bodied parents (for example, they did not know what to say or that they doubted their ability of being a parent). The insecurity lasted only until they got to know the parents with an SCI.

\section{Network}

Among those who had children after their SCI, 15 (38\%) felt that they got advice before the pregnancy and birth. There was no significant difference between men (15\%) and women (22\%) $(P=0.10)$. Only 11 $(22 \%)$ felt that they got answers to their questions about what it is like to have small children as an SCI parent. Mostly they had the answers from their midwife (four responders).

Twenty-one participated in mother/father groups, with a significant difference between women $(67 \%)$ and men $(23 \%)(P=0.003)$. Eleven of the comments to the question 'Has there been anything you have missed' were about not having a person in the same situation to talk to and share concerns with. The following comment by a male with tetraplegia illustrates this:

Was unfortunately not in a fathers group because I had to have one helper to play with the baby.

I've missed sharing concerns, experiences, get advice, be confirmed as a parent of peers, other wheelchair users or others who might be acquainted with my problems. I was almost depressed, but drove on and watched the child, went out, slept too little, was not thinking about my needs. Could not share my real concerns besides trivial new father and mother issues.
Table 4 Good advice from the responders to other men/women in the same situation

See the possibilities, not the limitations.

A good advice for keeping your family has to be to count +-points. Give every single thing you experience in your everyday life a +-point (e.g., my wife, my beautiful wife gets down the stairs and is happy- one +-point). Another good advice for keeping your family is to accept your situation and work on how to get the best out of the new situation. There is nothing that is so bad that it is not good for something else. It's all about finding the good things so you do not end up like an old, bitter man (or woman).

Remember to get a good relation to the municipalities.

Never take no for an answer, use, for example, RYK, Danish Federation for the Disabled. The independent consultant on the disability field can help and advice one on how to appeal about a no/refusal in your application to the municipality. It gets easier to be the mother you want to be the older the child gets, in the mean time it's all about finding the best possible way to be as close as you can to your child. I cannot recommend enough to get down on the floor, where you can be close to your child. I would recommend you to study the law of Social Services and decide to fight for a good life. It's not the municipalities' decision it's YOUR'S. Fortunately, even the municipalities have to follow the law, even though they will try to convince you otherwise.

Seven of the other provided comments were about the difficulties in the cooperation with the municipalities: for example, in not getting the help or aids needed.

\section{Good advice for others}

The advice for other women and men with SCI revealed that 13 responders' approach was to encourage those who want to become parents. For the parents-to-be, nine responders stated that they would suggest getting in contact with other parents with SCI, in order to get ideas of simple solutions to daily challenges. Contacting the mentoring program in RYK (SCI consumer organization) was also suggested by two responders. Table 4 lists some of the advice given by the participants.

The advice for the municipalities, in combination with the answers to the above question 'Have there been anything you have missed?', revealed a dissatisfaction by $21(34 \%)$ parents. The dissatisfaction was about the difficulties in obtaining help from the local authorities. This included not being able to get the personal assistant they needed (four comments) or that the necessary mobility aids were not allocated (four comments) and that the municipalities did not show any understanding of their situation as parents with an SCI (three comments). These comments came from both genders, as well as from persons with tetraplegia and paraplegia. The municipalities were thus advised to improve in relation to financial support for mobility aids and personal assistance in order to make it easier for individuals with SCI to fulfill their parenting role. The municipalities were also advised by one parent as follows:

More information about individuals with a spinal cord injury who have some ability to walk. It is hard being walking with a spinal cord injury and be in need of aids like wheelchairs. I think that the municipalities do not have that much information/understanding.

\section{DISCUSSION}

Our study indicates a very high general satisfaction of the SCI parental role, which is consistent with findings from previous studies. ${ }^{1,8-10}$ 
Most of the parents in the present study have not met any negative treatment from the parents of their children's' mates in the childcare institutions or school: only helpfulness and consideration. The sample felt that they generally had the same access to the parent meetings as able-bodied parents, but there were some environmental barriers. The employment rate among the parents with an SCI (men $83 \%$ and women $62 \%$ ) was relatively high, when considering the employment rate among Danes in general in 2014 was $73.5 \%$ at the age of 15-64 years, $76.2 \%$ for men and $70.8 \%$ for women. ${ }^{11}$ However, these figures are not directly comparable, because the parents with an SCI were just asked whether they had been employed at some time during their children's' first 10 years. It gives the individuals with SCI higher life satisfaction and sense of well-being and better self-esteem to be employed. ${ }^{6}$ Our study indicates that it was easier to combine their job of being a parent with part-time employment. Similar findings regarding employment are described by Aune. ${ }^{12}$ In addition, it is reasonable to presume that individuals with more resources/less premorbid psychosocial problems are more likely to have children and to be able to respond to the questionnaire distributed in the present study. Regardless, the findings described above are encouraging to women and men with SCI who wish to become a parent post injury.

There are good possibilities regarding circumventing environmental barriers outside the home (for example, parent meetings not held on the ground level or not having toilets for disabled), having in mind that the parent meetings typically are planned months in advance. It indicates a great need for clearer guidelines for childcare institutions/ schools about how to make consideration to parents in wheelchairs (for example, when planning a parent meeting, consider the physical premises: whether there are stairs without access to an elevator, are there toilets for disabled nearby and is there place for a wheelchair).

Our study indicates that 17 of the respondents could breastfeed without aids/help, with no significant difference between women with paraplegia and tetraplegia. However, it is well known that women with tetraplegia have the absence of sympathetic innervation to the breasts and impaired milk production and that successful maintenance of breastfeeding is only possible with special training. ${ }^{2,13,14}$ An explanation for not finding this difference in our sample may be because of the relatively few women participants.

Seventy-three percent of the responders did not feel that they got their questions about what to expect as a parent with an SCI to small children answered. A couple of parents did not know that some of the aids mentioned in the questionnaire existed. This knowledge suggests that the information given to the parents or parents-to-be is not sufficient.

As the comments from the responders illustrate, there are several parents in the study who express a need to get into contact to other parents in the same situation. This was also stated by Tebbet and Kennedy: 'Women with first-hand experience of the event were seen as providing a valuable insight, and women who had not spoken to mothers with SCI reflected that they would have found this useful. ${ }^{5}$ This is similarly described by Kaiser et al. ${ }^{8}$

The usual mother/father groups were not always efficient for the parents with an SCI, because the issues of the parents with an SCI encounter are not always comparable to the issues able-bodied parents are facing.

Personal assistance is a necessity for some of the parents with an SCI who rely on help to have their everyday life needs met. There are, as seen among two of the comments an ambivalence regarding receiving personal help for fulfilling their parenting roles. On one hand, the help gives the parents more energy for their family and work. Conversely, it is hard to see someone else take care of their child, which fosters a lack of privacy, as there is a 'stranger' present all the time.

The ambivalence of receiving personal assistance and the need for more support from the authorities are also described in two previous studies by Shpigelman ${ }^{15}$ and Prilleltensky. ${ }^{16}$ Although the studies were based on mothers with different types of physical disabilities (cerebral palsy, muscular dystrophy, paralysis caused by polio virus, SCI and so on), it is reasonable to believe that it is similar for both mothers and fathers, with varying kinds of disabilities, including SCI. The two studies, one from Israel and the other from Nashville (USA), indicate the same problems as in our study (that is, challenges are the same regardless which of these countries the individuals with disabilities are living in). It would be interesting to further investigate the negative impact of having professional help in relation to the intimate contact to one's children and the impact on the persons' self-esteem as a parent.

The majority of the parents (92\%) had a car, which is consistent with an earlier Danish study on access to transportation post SCI, in which $86.4 \%$ of 236 individuals with SCI had a car. ${ }^{17}$ The use of the above listed aids was lower than 50\%; taking into consideration that the aids facilitate the daily living and give the parents more independence, the usage seems to be low. Some of the responders have expressed their dissatisfaction regarding the difficulties in obtaining the needed aids; this dissatisfaction has also been described in a previous study. ${ }^{8}$ Each parent should probably be evaluated for the need of such aids. In case the aids are considered relevant, the parents should be informed about the possible alternatives of aids that may facilitate their daily living. The fact that three of the participants were not even aware of the existence of the listed aids could indicate the need of more information about the available aids for parents with an SCI. A study conducted in Denmark showed that only 62 participants out of 236 regularly got information about new aids. ${ }^{18}$

\section{Suggestions}

- Development of detailed guidelines for health-care professionals and childcare institutions/schools about how to minimize the environmental barriers for individuals with an SCI-as well as other wheelchair-bound parents-for them to be on equal terms with able-bodied parents (for example, ensuring that the parents' meetings are held in a place where parents in wheelchair can access without additional help). In addition, a wheelchair-accessible toilet should be available.

- Detailed guidelines for social workers in the municipalities should be designed in order to ensure that they could do their job without misunderstanding the existing laws and regulations.

- Every interested parent with SCI should at the time of the birth of their child/at the time of the injury if having children should be evaluated regarding their need for special (mobility) aids.

- A guideline on what to expect as a parent with an SCI should be developed and should be made available in hospitals/institutions involved with the care of individuals with SCI. The guidelines should be directed to both individuals with SCI becoming parents and parents who acquire an SCI.

- Investigate the possibility of establishing parent groups for parents in wheelchair.

If each parent is given the optimal support regarding mobility aids for example, there is a possibility that there would not be a need for a personal assistant, which is far more expensive. Alternatively, it could 
reduce the number of hours needed for a personal assistant. This could, for example, be done by a social worker in collaboration with an occupational therapist who could visit the parent with SCI before the child is born, which is when most parents typically buy most of the equipment used for the child at this time and inform them about the possible aids and what could be relevant. Shortly after birth, another visit should take place in order to make a precise evaluation of what is needed for the parent with SCI to ensure that they can be as independent as possible.

The obtained knowledge will also be made available for individuals with SCI considering becoming parents.

\section{Limitations of the study}

The questionnaire used for this investigation has only been tested in three persons, and therefore some of the questions might not have been clear enough, and were thus left unanswered. Some of the questions were answered with both yes and no, which also indicates that some of the questions might need to be more detailed or precise.

The questions in our questionnaire are very general, and therefore might have contributed to difficulties in answering some of the questions. For example, some questions might need to be tailored for those who sustained their SCI after their children were born vs those who had their children post SCI.

The etiology of the SCI was not asked in the questionnaire. Whether this may have influence on the results is not known.

Because of the wide age-range of the responders, some of the answers can be misleading because, for example, some of the existing aids did not exist 30 years ago and the existing laws were not comparable to those that were in place $20-30$ years ago.

\section{CONCLUSION}

The study shows that the major issue for parents with an SCI is the lack of help from their municipalities. Regardless, the majority of the sample were generally very satisfied with their parenting role and they all encouraged other individuals with SCI who want to become parents 'to do it'. This indicates, just as the report from The Danish Society for Human Rights suggests, that there is a need for better and clearer laws and guidelines for the social workers regarding how to give the best support to the parents with disabilities.

\section{DATA ARCHIVING}

There were no data to deposit.

\section{CONFLICT OF INTEREST}

The authors declare no conflict of interest.

\section{ACKNOWLEDGEMENTS}

We thank Birgitte Bjørkman, editor of RYK! and a parent with an SCI, for inspiration and help to develop the questionnaire and to help finding participants to this project. We also thank Susanne Dalgaard Døssing, nurse at Department of Neurology-Spinal Cord Injury Centre of Western Denmark, Viborg Regional Hospital, for helping to find participants to this project.

1 Westgren N, Levi R. Motherhood after traumatic spinal cord injury. Paraplegia 1994; 32: 517-523.

2 Cowley KC. Equipment and modifications that enabled infant child-care by a mother with C8 tetraplegia: a case report. Disabil Rehabil Assist Technol 2007; 2: 59-65.

3 United Nations. Article 23 - Respect for home and the family. Available from http:// www.un.org/disabilities/default.asp?id=283. United Nations Enable; 2014 [cited 21 September 2014].

4 Bendixen C, Ventegodt-Liisberg M, Justesen P, Munck S. Ret til at være forældre: Institut for Menneskerettigheder. Available from http://menneskeret.dk/files/ media/dokumenter/udgivelser/ret_til_at_vaere_foraeldre_pdfa.pdf (accessed 1 September 2015).

5 Tebbet M, Kennedy P. The experience of childbirth for women with spinal cord injuries: an interpretative phenomenology analysis study. Disabil Rehabil 2012; 34: 762-769.

6 Lidal I, Huynh TK, Biering-Sorensen F. Return to work following spinal cord injury: a review. Disabil Rehabil 2007; 29: 1341-1375.

7 Duvdevany I, Buchbinder E, Yaacov I. Accepting disability: the parenting experience of fathers with spinal cord injury (SCI). Qual Health Res 2008; 18: 1021-1033.

8 Kaiser A, Reid D, Boschen KA. Experiences of parents with spinal cord injury. Sex Disabil 2012; 30: 123-137.

9 Alexander CJ, Hwang K, Sipski ML. Mothers with spinal cord injuries: impact on marital, family, and children's adjustment. Arch Phys Med Rehabil 2002; 83: 24-30.

10 Atterbury JL, Groome LJ. Pregnancy in women with spinal cord injuries. Nurs Clin North Am 1998; 33: 603-613.

11 Denmark S. AKU120: Labour force status in percentage by employment status, age and sex: Statistics Denmark; 2015. Available from http://www.statistikbanken.dk/ statbank5a/SelectVarVal/Define.asp? MainTable=AKU120\&PLanguage $=1 \& P X S I d=0 \&$ wsid $=$ cftree.

12 Aune G. Everyday challenges for mothers with spinal cord injury: a qualitative study. Scand J Disabil Res 2013; 15: 185-198.

13 Liu NK, Krassioukov AV. Postpartum hypogalactia in a woman with Brown-Séquard-plus syndrome: a case report. Spinal Cord 2013; 51: 794-796.

14 Signore C, Spong CY, Krotoski D, Shinowara NL, Blackwell SC. Pregnancy in women with physical disabilities. Obstet Gynecol 2011; 117: 935-947.

15 Shpigelman CN. How to support the needs of mothers with physical disabilities? Disabil Rehabil 2015; 37: 928-935.

16 Prilleltensky O. A ramp to motherhood: the experiences of mothers with physical disabilities. Sex Disabil 2003; 21: 21-47.

17 Biering-Sorensen F, Hansen RB, Biering-Sorensen J. Mobility aids and transport possibilities 10-45 years after spinal cord injury. Spinal Cord 2004; 42: 699-706.

18 Biering-Sorensen T, Hansen RB, Biering-Sorensen F. Home aids and personal assistance 10-45 years after spinal cord injury. Spinal Cord 2009; 47: 405-412.

Supplementary Information accompanies this paper on the Spinal Cord website (http://www.nature.com/sc) 